\title{
Review on Analysis of Engine Mounting Bracket
}

\author{
Sanket Gaikwad, M.Tech Student, SOET Sandip University,Nashik,India,sgsanket30@gmail.com \\ Prof. Arif Mansuri, Dean Administrative, SOET, Sandip University, Nashik, India. \\ Mr. Monish Wasnik, Professor, SOET, Sandip University, Nashik, India.
}

Abstract: Engine mounting bracket plays an important role in reducing vibration as well as noise. It is one of the main component of engine mounting assembly. The purpose of an engine mounting bracket is to support the power train system and to properly balance the engine. This paper includes the study of FEA analysis and optimization of existing engine mounting bracket. The CAD model is designed on basis of previous used bracket and Analysis is done in ANSYS Software. After analyzing it, the portion of bracket which gets failure is redesign and analyze again so that the modified bracket will sustain at new loading condition.

\section{Keywords: Engine mounting system, finite element analysis, optimization.}

\section{INTRODUCTION}

Now each day the necessity for lightweight structural material is increasing as there's loads of sorts in fuel consumption reduction and improvement in decreasing the emission. The magnitude of production volumes has traditionally placed severe wants on the robustness of the tactic used in manufacturing. In some studies, the brackets unit of measurement discovered to possess saved 38th of the mass. Structural optimization could be a vital tool for associate optimum design; comparison in terms of weight and half performance structural optimization techniques is an economical tool to produce higher quality product at a lower price. The demand for higher activity engine mount brackets should not be offset by a rise within the merchandise prices and/or development cycle time. In a heat engine, the engine mounting bracket is that the key disadvantage as there's a unit throttled conditions and also the next compression quantitative relation and even their unit of measurement loads of speed irregularities at low speed and low load compared to petrol engines. therefore because of this, there is a heap of vibration excitation. With this vibration motor, the mounting bracket can fail, so by optimizing the shape and thickness of the motor mounting bracket, we have a tendency to area unit able to improve performance at initial style stages.

\section{PROBLEM STATEMENT}

The current engine mounting bracket is used for bh4 engine at it respective loading condition in same case this bracket is using for BH6 engine. But due to change in engine as well a loading condition the bracket used in bh4 engine is getting failure in new engine so we have to design new bracket which can sustain at loading condition of bh6 engine.

In this paper, we have a tendency to attend the analysis for the present Engine mounting bracket, with similar dimensions, later by knowing the results of the FEA we will then alter the look of the bracket the maximum amount as attainable to scale back the stresses. Generally, from the literature survey, we have a tendency to found that the bracket fails at high engine speed. Also, the load of the engine is supported by the bracket therefore analysis should visualize for stress concentration within the bracket.

\section{LITERATURE REVIEW}

Mr. Pramod Walunje, V.K. Kurkute [1], in this work they have within the main target on the employment of lightweight material for mounting bracket and in addition to chop back the load of the engine mounting bracket. Here the burden of the fabric is reduced and first two process is disbursed and even with this, an experimental setup is an in addition accustomed notice the strain level of the materials ascertained determined that number thirteen alloy have good natural frequency and stresses square measure among the yield strength, so by considering the number thirteen and reducing its thickness further by $2 \mathrm{~mm}$ than the initial half, they found that presently, von misses stresses square measure inside yield stress.

Sandeep Maski, Yadavalli Basavaraj [2], In this paper they have given attention on best material foe engine mounting bracket to stand at high strength and high vibrations. From conclusion of this paper it shows that natural frequency of cast steel is better than forged iron. Therefore, cast steel preferred for modelling the engine mounting bracket. Hence they have focused on strength and vibrations as they are important parameters of styling an engine mounting.

Dr. Yadavalli Basavaraj, Manjunatha.T.H [3], the analysis results that are obtained from two-arm, three-arm, four-arm, filler arm and 4 arm symmetry engine mounts within which of 4 arm symmetry engine mount curve obtained from LSDyna approach follows precisely the experimental take a look at the curve and also this style has the best natural frequency amongst all design iterations. The higher than work indicated that the rubber utilized in the engine mount 
had increased the frequency from one. $2 \mathrm{~Hz}$ (basic design) to one. $8 \mathrm{~Hz}$ (four-arm symmetry). because the style is dynamical in rubber, the mode of frequency will increase and it's found that one. $8 \mathrm{~Hz}$ is that the frequency for the four-arm symmetry mount style.

P.D. Jadhav, Rama krishna [4], this work could be a contribution to the event of recent material for engine mounting bracket. The results obtained for the static structural and modal analysis have shown that the $\mathrm{Mg}$ is healthier than atomic number 13. From the results, it is seen that the $\mathrm{Mg}$ bracket is safe for the specified application. it'll facilitate in decreasing the burden of the ability train assembly, which might increase fuel potency. The $\mathrm{Mg}$ bracket is factory-made with less quantity of your time and it possesses longer life compared to an atomic number 13 bracket. the most drawback of using magnesium rather than atomic number 13 is its higher cost; however recent studies have shown that the distinction between prices of atomic numbers 13 and $\mathrm{Mg}$ is decreasing. so it is over that $\mathrm{Mg}$ is most well-liked over atomic number 13 as a fabric for an engine mounting bracket. analysis within the direction of implementing the $\mathrm{Mg}$ engine mounting bracket rather than atomic number 13 bracket has conjointly proved that $\mathrm{Mg}$ brackets square measure higher in numerous operating conditions.

Monali Deshmukh, K R Sontakke [5], during this paper, they have studied vibration damping of an engine mounting bracket. If the brackets have their resonance frequencies near to the operative engine frequencies, then the big amplitude of vibration gets generated which can cause its fatigue failure or breakage, therefore reducing it's calculable or desired life. And if the harmonic response values of the bracket square measure quite the suitable vary it leads to the generation of noise. therefore it's needed to see the harmonic response of the designed bracket. Vibration damping will be either provided by using separate dampers or by appropriately deciding the fabric and dimensions of the brackets. throughout its operation, the unsought vibrations generated by the engine and road roughness will get directly transmitted to the frame through the brackets. this could cause discomfort to the traveler or vibrations that may even injury the chassis. the prevailing bracket style is optimized to fulfill the higher than necessities.

B. Shreedhar, U. Kamarupa Sashidhar [6], on topology optimized model finite component analysis, has disbursed for traditional mode, FRF and strength analysis and complete constant quantity study has disbursed by mistreatment HyperStudy. during this paper, a topology optimization approach is bestowed to form an innovative design of an engine mount bracket. Final comparison in terms of weight and part performance illustrates that structural optimization techniques are effective to provide higher quality products at a lower price.
Vinay Patil and Mahindra Gaikwad et.al [7], In this paper they have designed mounting bracket of Associate in Nursing automotive and targeted on to figure out natural frequencies of automotive engine mount bracket. They have thought about the three materials for engine mount bracket that is atomic number thirteen alloy, $\mathrm{Mg}$ alloy, gray castiron once the modal analysis is disbursed, it's found natural frequencies of gray cast-iron is low which may prove plenty of hindrance within the vibration of engine mount bracket so as that they need eliminated gray cast-iron, in terms of study atomic number 13 alloy and $\mathrm{Mg}$ alloy unit of measurement showing nearly getting ready to value the price the value of natural frequency in smart terms as $\mathrm{Mg}$ alloy has higher strength that is low-stress worth, so ideally $\mathrm{Mg}$ alloy is chosen as higher material by the study.

\section{CAD MODEL GENERATION}

The Engine bracket is especially consisting of 2 components, in the main inner and outer half. CAD model then is formed by the commands in CATIA of Pad, pocket, fillet, and geometrical choices partially style module. constant generation of drawings can facilitate to urge the size helpful in forces calculations in static loading conditions on a part.

In this, mounting bracket is drawn in CATIA as per given dimensions of actual model. For modeling commands like fillet, extrude, hole, chamfer etc. are used. For forces calculation in static loading condition drawing of parametric generation will help to get the dimensions. While modeling the bracket the dimensions given should be accurate so that the result required from ansys will be shown accurate. Otherwise after manufacturing the model testing result will be different from result obtained from ansys software.

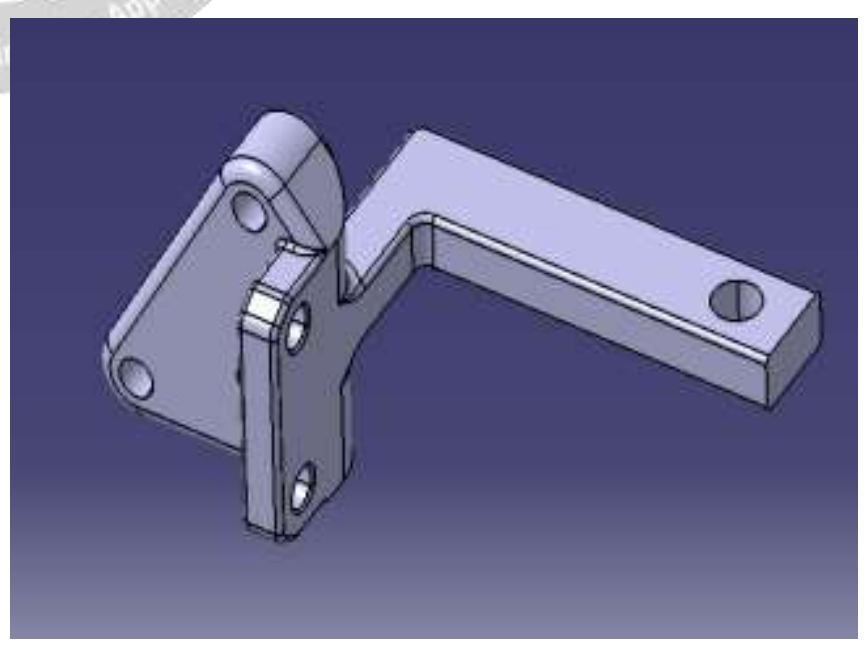

Fig. 1: Bracket design in CATIA V5

\section{STATIC STRUCTURAL ANALYSIS}

An engine mounting bracket is taken for analysis.

Finite element technique is a numerical technique in which the complex structure is divided into number of small 
components which are referred as finite components. This number of small parts are connected to each other by small points which are known as nodes. To solve the equation of finite element technique uses algebra therefore this are referred to as structural analysis and turning it into primary analysis for designers and analysis.

The 3 basic FEA method is

a) Preprocessing section

b) process or answer section

c) Post-processing section

Static structural analysis is that the analysis displacements, stresses, strains and forces on a structure or a part thanks to load application. The structures response and masses are assumed to vary slowly with relation to time. There are varied varieties of loading which will be applied during this analysis that are outwardly applied forces and pressures, and temperatures.

The information required for the analysis of the bracket is as follows:

i) Material properties:

young's modulus, poisons ratio, density, yield strength values for mild steel are taken.

ii) Meshing:

A solid element mesh is required to be generated. The meshing of the mounting bracket is done as triangular

mesh with 212347 Number of Nodes and 123291 numbers of elements. In this model triangular meshing is used to divide the parts into small components. In meshing component should be divided into possible finite small components, because as large as part is divided, the result will be very accurate.

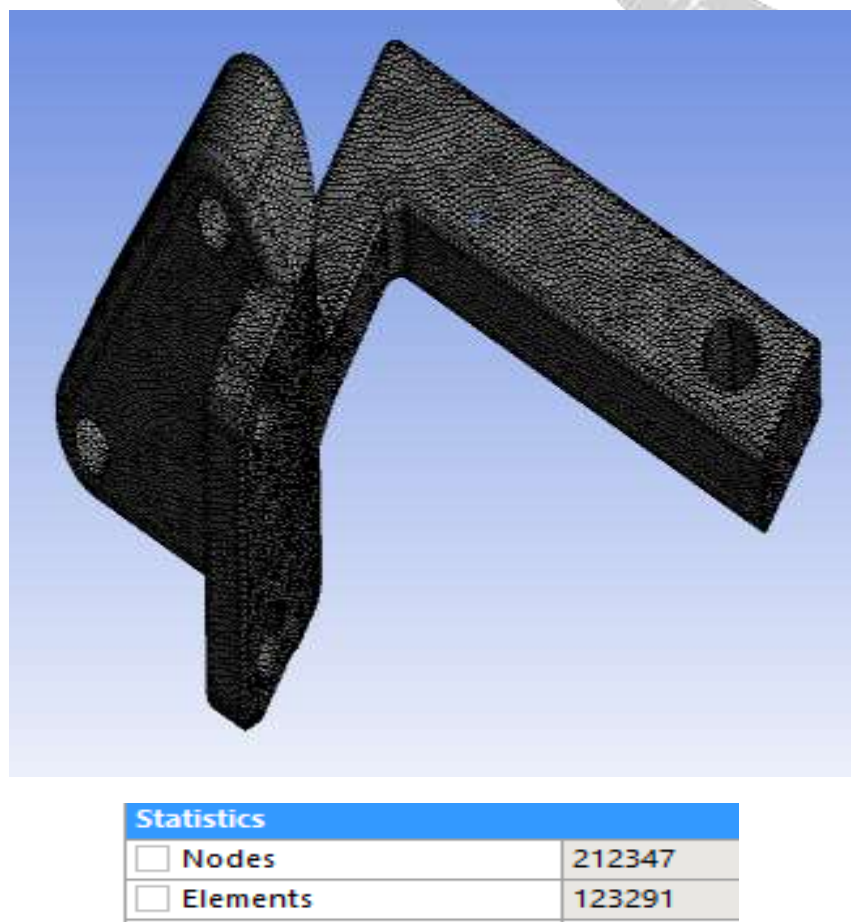

Figure 2: Meshing of Engine Bracket

\section{iii) Loads:}

Specific values of load are implemented for a typical mounting bracket. The load is taken as $1252.5 \mathrm{~N}$ which is considerable as the distributed weight of the engine is less than this value. This load taken to know the area at which failure is occurred. After the area is known where the failure is occurred then the next process is to redesign the part for minimize the failure so that it will be used for new assembly of engine mounting system.

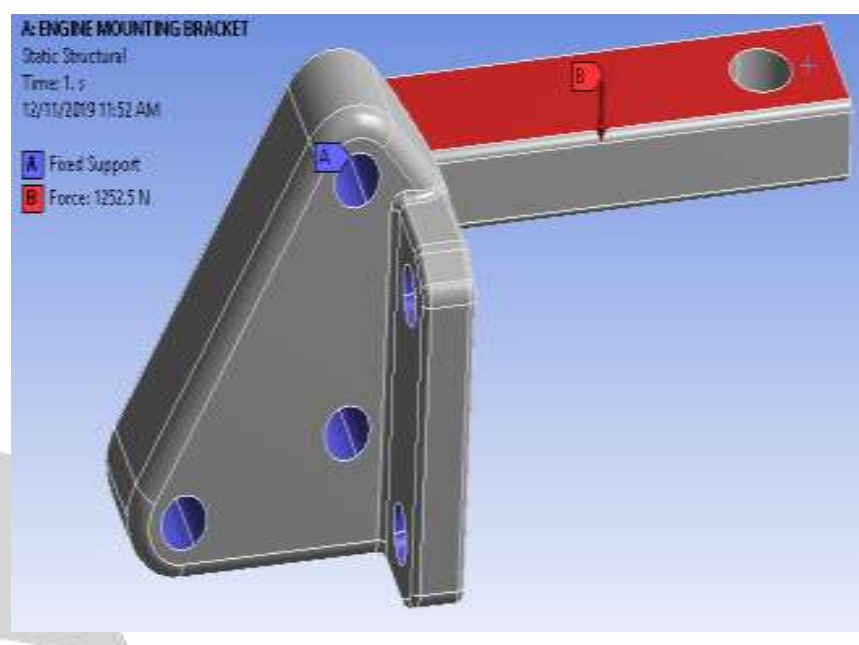

Figure 3: Boundary Condition to Engine Bracket

iv) Constraints:

The nodes around the bracket mounting holes have a rigid element connecting them to the center of the hole which has of its degree of freedom fixed. The element which is used to fix engine mounting bracket and body of the vehicle is fixed by constraining six degrees of freedom.

The FE mesh together with the loads and constraints is made in the meshing environment. Solver deck is prepared for carrying out static analysis. The geometry is exported to .Cdb format to run into ANSYS.

Post-processing is done in ANSYS. Following are the results for post processing.

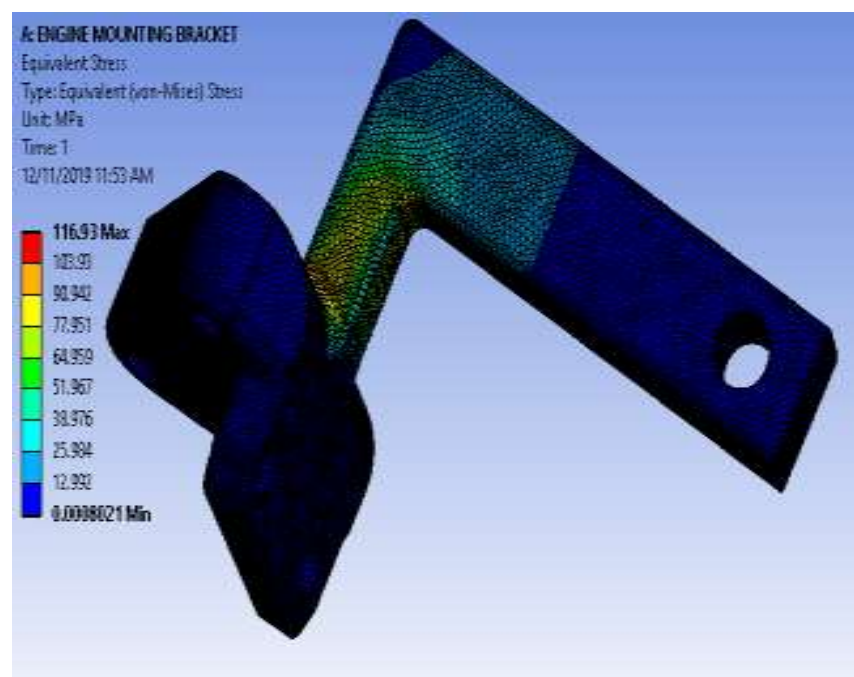

Figure 4: Equivalent stress on Engine Bracket 
Stress value for engine mounting bracket is $116.93 \mathrm{MPa}$ which is the preliminary stage value. In next modified design stage we have to minimize the von-misses stress as minimum as possible to made design safe.

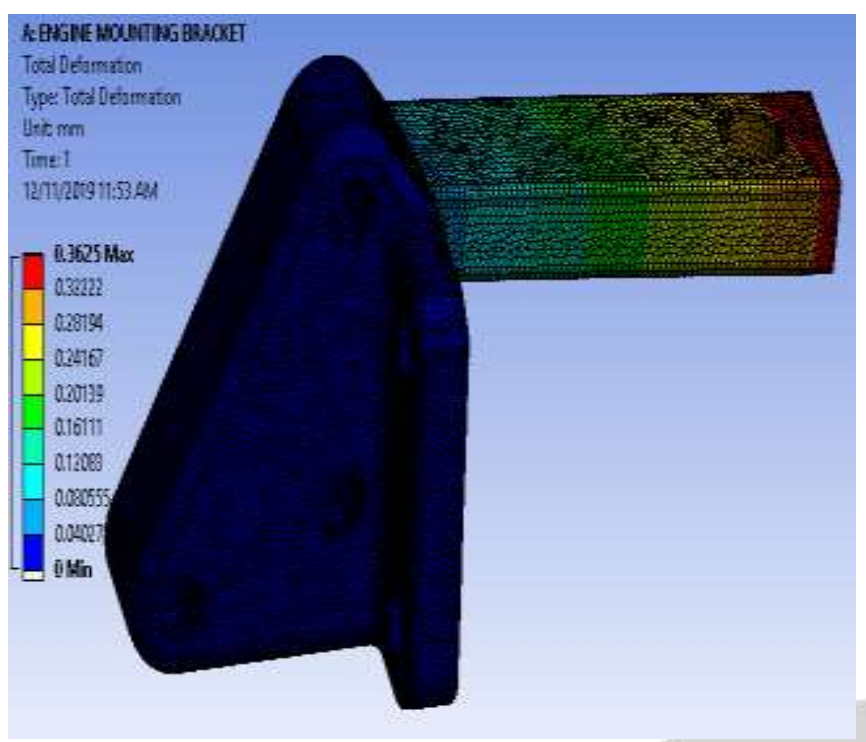

Figure 5: Deformation plot

From above, deformation for engine mounting bracket is $0.3625 \mathrm{~mm}$. which is very high for current assembly work so in next stage the value of deformation must be less as possible from this so that it will be safe design for assembly and for load carrying.

This von-misses stresses and deformation will be reduced by adding the material at the failure portion, number of iteration should be done to convert this design to safe design.

\section{CONCLUSION}

The Analysis of engine mounting bracket is attempted by applying new boundary conditions. From this analysis it is seen that at new conditions of engine mounting bracket previous engine mounting bracket get fails. The design has to analyze and modify from its preliminary stage. The addition of material may help in minimizing stress and deformation at the joint. But after adding material the weight of material will get increased so, these weight can be reduced by weight optimization of the bracket.

\section{REFERENCES}

[1] Mr. Pramod Walunje, V.K. Kurkute, "Optimization Of Engine Mounting Bracket Using FEA”, IJR, Volume 2,Issue 12, Dec 13.

[2] Sandeep Maski, Yadavalli Basavaraj, "Finite Element Analysis Of Engine Mounting Bracket By Considering Pretension Effect And Service Load", International Journal Of Research In Engineering And Technology, Volume 4, Issue 08,Aug 2015.

[3] Dr. Yadavalli Basavaraj, Manjunatha.T.H, "Design Optimization Of Automotive Engine Mount System”, International Journal Of Engineering Science Invention, Volume 2, Issue 3, March 2013.
[4] P.D. Jadhav, Rama Krishna, "Finite Element Analysis of Engine Mounting Bracket", IJAET,Volume 1, Issue 4, September 2014.

[5] Monali Deshmukh, K R Sontakke, "Analysis and optimization of engine mounting system”, IJSER, Volume 3, Issue 5, may 2015.

[6] B. Shreedhar, U. Kamarupa Sashidhar, "Optimization of Mounting Bracket”, HTC 2012.

[7] A.S.Adkine et.al “.Design And Analysis Of Engine Mounting Bracket Using Ansys Tool" International Journal of Innovation in Engineering, Research and Technology [IJIERT]2016

[8] Jasvir Singh Dhillon, et.al"Design of Engine Mount Bracket for a FSAE Car Using Finite Element Analysis" Int. Journal of Engineering Research and Applications.2015

[9] Gabriel-Petru Anton, Mihai Paval, Fabien Sorel, “Application on an updated finite element model of an engine in the automotive industry" Sisom 2011 and Session of the Commission of Acoustics, Bucharest 25-26 May.

[10] Senthilnathan Subbiah, O.P. Singh, "Effect of muffler mounting bracket designs on durability", Engineering Failure Analysis 18 (2011) 1094-1107.

[11] Waleed F. Faris, "Fatigue analysis of Package Terminal Air Conditioner motor bracket under dynamic loading", Materials and Design 30 (2009) 3206-3216.

[12] S. Irving , Ferguson-Smith, X.Z. Hu, Y. Liu, "Comparative fatigue assessment of soft toe and nested bracket welded aluminum structures", Engineering Failure Analysis 12 (2005) 679 690.

[13] Jasvir Singh, Dhillon, et.al "Design of Engine Mount Bracket for a FSAE Car Using Finite Element Analysis" Int. Journal of Engineering Research and Applications.2015. 